\title{
Silicon Carbide MOSFET Traction Inverter Operated in the Stockholm Metro System Demonstrating Customer Values
}

\author{
Martin Lindahl $^{* \dagger}$, Erik Velander ${ }^{\dagger}$, Mikael H Johansson ${ }^{\dagger}$, Anders Blomberg ${ }^{\dagger}$ and Hans-Peter Nee* \\ *KTH Royal Institute of Technology, Stockholm, Sweden \\ ${ }^{\dagger}$ Bombardier Transportation, Västerås, Sweden \\ E-mail: martlin@kth.se
}

\begin{abstract}
For the first time results are reported in literature of a successful field test using a silicon carbide ( $\mathrm{SiC}$ ) metal-oxidesemiconductor field-effect transistor (MOSFET) traction inverter operated in the field. The metro train has been operated over a period of 3 months on the Green Line in the Stockholm metro system. Increased traction converter power density with a volume reduction of $51 \%$ as well as a weight reduction of $22 \%$ have been achieved. Lower power losses allow the use of car motion cooling. From complementing measurements in the laboratory of silicon and $\mathrm{SiC}$ in the same power device package with varying switching frequencies considerably lower $\mathrm{SiC}$ temperatures can be reported.
\end{abstract}

Index Terms-Silicon carbide (SiC), SiC MOSFET, power semiconductor devices, AC motor drives, electrical traction, railway, metro, field test.

\section{INTRODUCTION}

Mankind has to face several great challenges regarding use of resources and climate change. Contributing to both these challenges is the use of energy for transportation. In this sense, electric traction is superior when comparing to transportation based on internal combustion engines. The electric energy used to supply the electric train is, however, often generated using coal, gas, or liquid fossil fuels. It is, therefore, important that the efficiency of the drive system is very high. Also, if the electric energy is generated using renewable energy sources it makes sense to reduce the energy consumption, because this reduces the need for energy generation using sources that generate carbon dioxide.

In this perspective, the introduction of silicon carbide ( $\mathrm{SiC})$ power devices seems very attractive. Recently, SiC metaloxide-semiconductor field-effect transistors (MOSFETs) have become available in ratings and power modules suitable for electric traction [1]. The most obvious benefit of SiC MOSFETs compared to silicon ( $\mathrm{Si}$ ) insulated-gate bipolar transistors (IGBTs) with voltage ratings in the $1.7-6.5 \mathrm{kV}$ range is a significant reduction in switching losses [2]. In [3] a $55 \%$ reduction in switching losses is reported for a $3.3 \mathrm{kV}$ module prepared for traction use. Reductions in total power losses of $70-80 \%$ have been reported [1], [4]. Another important advantage is that the conduction losses can be chosen through the choice of total chip area [5], [6]. This is an advantage of the MOSFET which does not have the built-in potential

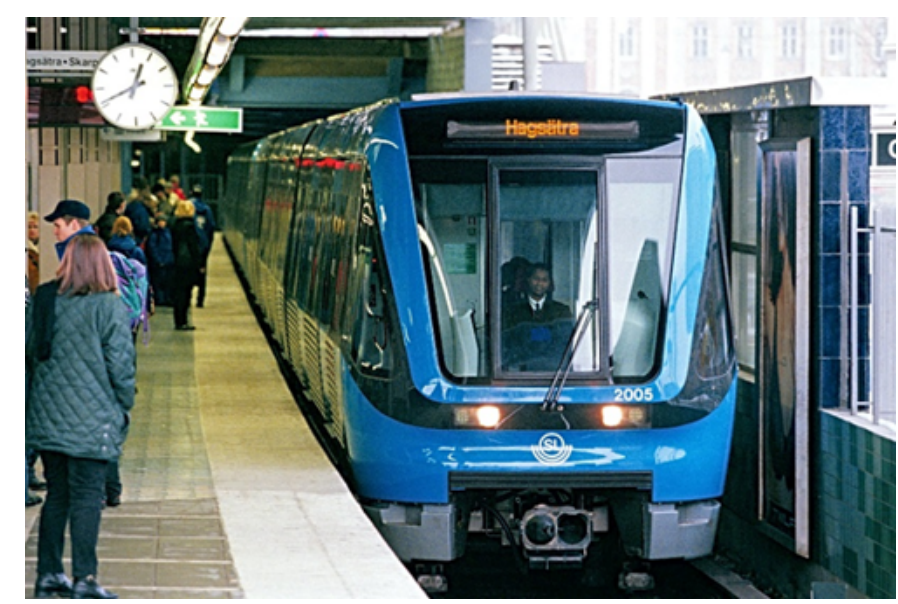

Fig. 1. Photo of a metro train of type C20 operated in Stockholm Metro. The SiC traction demonstrator inverter has been operated in revenue service with passengers on a train of this type.

(knee voltage) which is the case of the IGBT, so that the conduction losses are substantially lower at low and moderate converter output load [7]. In addition, this results in significant reductions in conduction losses if an increased investment is made in the total number of semiconductor chips.

Apart from the energy savings, several additional benefits can be obtained on the system level using SiC MOSFETs. Due to the lower losses, the need for cooling is reduced. Cooling components like heat sinks and fans can be made smaller, which reduces the volume, weight and cost of the system [8]. It may also be possible to remove fans [7], [8] and use only the motion of air resulting from the motion of the vehicle itself, as in the application reported here. Benefits of this may be a higher reliability, lower maintenance costs and a lower acoustic noise level on the platform and in the cabin.

The lower switching losses open the possibility to operate at higher switching frequency. At higher switching frequency the harmonic losses of the traction motor can be reduced, where the reduced harmonic motor losses are even greater than the reduction of inverter losses. Another consequence of a higher switching frequency is lower magneto-acoustic noise within the spectrum humans can hear.

Despite these benefits, SiC MOSFETs still has not achieved 
widespread use. The main reason for this, in addition to the higher cost from the low volume of an emerging technology, is uncertainty of the reliability [9]-[12], mostly in terms of leakage currents [13], [14] and short-circuit performance [2]. In addition, there are system aspects such as electro-magneticinterferance (EMI) and traction motor winding issues [15]. The present study aims to demonstrate the customer values of $\mathrm{SiC}$ power devices and to increase the confidence by proving a successful field demonstration. Reliability studies on the module level have also started to bring more promising results [13], [14], [16].

With the demonstrator presented here, the overwhelming possibilities offered by replacing a Si IGBT inverter with a SiC MOSFET inverter have been evaluated and demonstrated in revenue service with passengers on a metro train in Stockholm. The train is shown in Fig. 1. A traction inverter was reported to be built in [1], [3]. This study is the first published successfully completed field test with $\mathrm{SiC}$ on a real train. The used $\mathrm{SiC}$ power modules are packaged in the new generation housing nHPD $^{2}$ [17], [18]. Increased power density with a volume reduction of $51 \%$ as well as a weight reduction of $22 \%$ have been achieved compared to the replaced original Si IGBT inverter.

Novel results are also presented of the semiconductor performance in the traction inverter for varying switching frequencies. Comparison is made with a state-of-the-art $\mathrm{Si}$ IGBT inverter with power modules also in the $\mathrm{nHPD}^{2}$ housing.

The outline of the paper is as follows. In Section II the demonstrator box is described. In Section III the measurement set-up and test conditions of the laboratory test are described, with the measurement results presented in Section IV. Results from the field test are presented in Section V. Finally, in Section VI the conclusions are drawn.

\section{SiC TRACTION INVERTER DEMONSTRATOR}

A demonstrator railway traction inverter using $\mathrm{SiC}$ semiconductors and car motion cooling has been built. The inverter is a two-level voltage source inverter and it is using a full$\mathrm{SiC}$ phase-leg semiconductor module in the new generation housing nHPD $^{2}$ with low commutation inductance optimized for high switching speeds. The new generation housing is a $100 \mathrm{~mm} \times 140 \mathrm{~mm}$ dual package developed for traction applications, and nHPD ${ }^{2}$ is a brand name from Hitachi for this housing. Other suppliers use other names for similar packages with the same footprint.

The original Si IGBT inverter was delivered in the mid1990 s and is rated for a nominal line voltage of $650 \mathrm{VDC}$. The rated continuous phase current is 400 Arms as supply for two motors connected in parallel. The demonstrator box contains two inverters which supply power to one motor each. The corresponding rated continuous phase current demanded in the application is therefore 200 Arms per inverter.

All power devices in this study use the same footprint and are rated $1.7 \mathrm{kV}$ as the nominal line voltage can be up to 900 VDC. The Si semiconductor modules are of type Hitachi

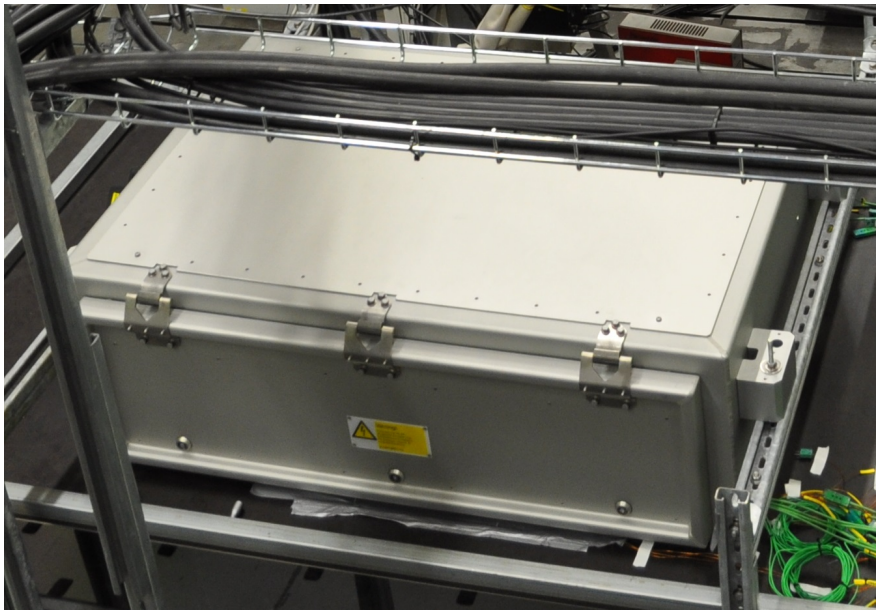

Fig. 2. Photo of the test object which is a railway traction inverter box with $\mathrm{SiC}$ semiconductors and car motion cooling.

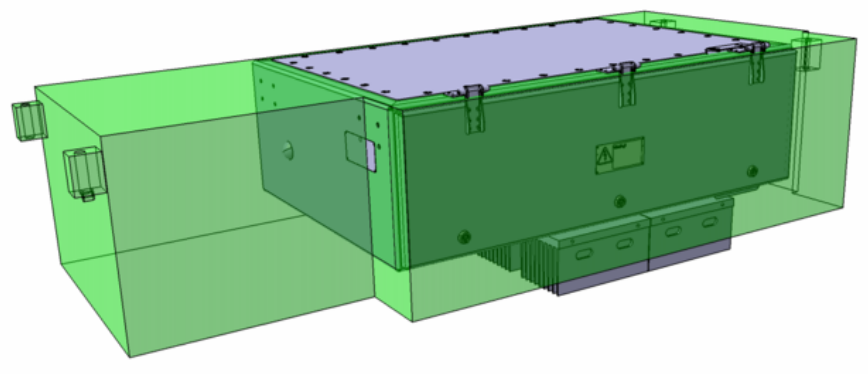

Fig. 3. Space envelope reduction is visualized. The volume of the original Si IGBT inverter shown in transparent green is reduced with $51 \%$ using the SiC MOSFET inverter. Weight is reduced with $22 \%$.

MBM1000FS17G and the SiC semiconductor modules are of type Hitachi MSM900FS17A.

The converter box is shown in Fig. 2 and in Fig. 3 a visualization is presented of the achieved volume reduction of $51 \%$ compared to the replaced original Si IGBT inverter on the train.

Two examples of switching wave forms are shown in Fig. 4 from a double pulse test circuit for one $\mathrm{SiC}$ semiconductor module of the type used on the train.

\section{MEASUREMENT SETUP OF THE LABORATORY TEST}

To complement the field test, and to investigate the performance of the SiC MOSFET inverter for switching frequencies which could not be investigated in the field test, a laboratory test has been performed. To produce the here reported temperature measurements, the demonstrator traction inverter was set up to supply a three-phase asynchronous motor, the same type of motor which is used on the train.

A comparison is made with $\mathrm{Si}$ and $\mathrm{SiC}$ modules of the same type of housing $\left(\mathrm{nHPD}^{2}\right)$ in the same converter box. Different types of heat sinks were used during testing: a heat sink with heat pipes for the $\mathrm{SiC}$ case and a heat sink without heat pipes for the $\mathrm{Si}$ case. In a separate test the cooling performances of these two coolers have been determined, and the measured 


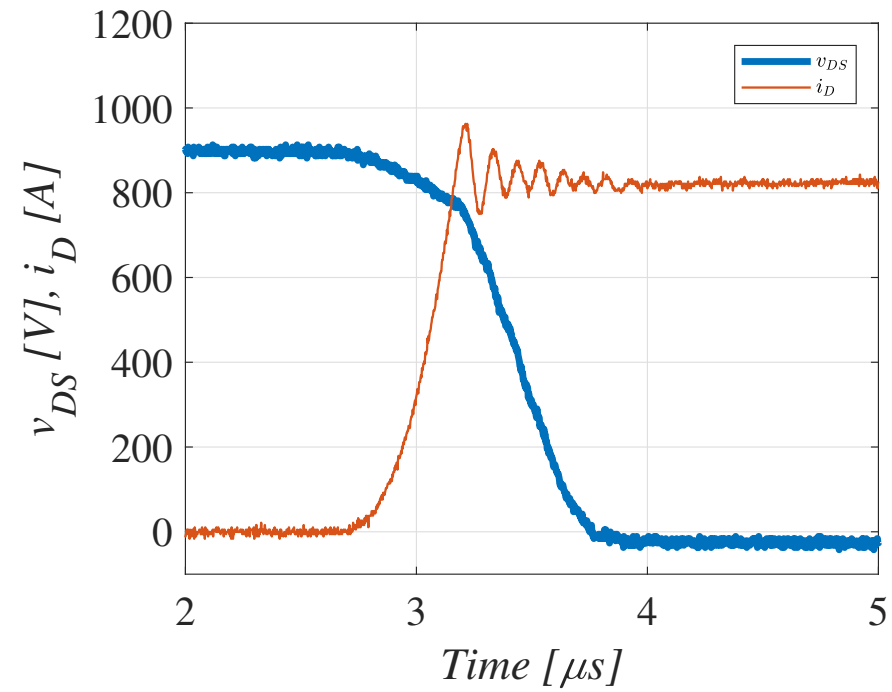

(a) Turn-on

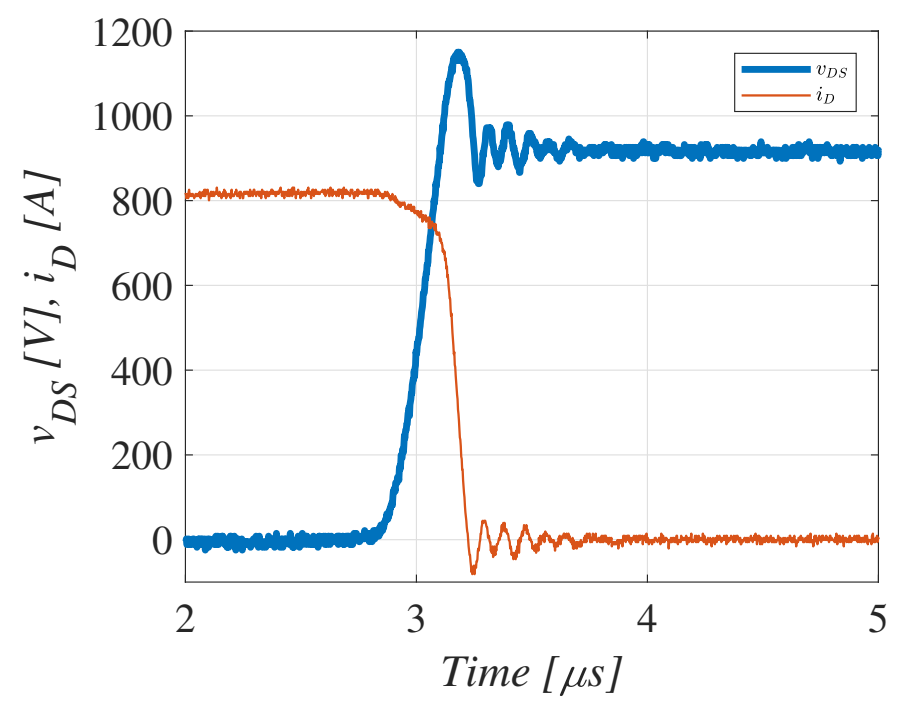

(b) Turn-off

Fig. 4. Switching wave forms with the type of $\mathrm{SiC}$ power module used on the train: (a) turn-on and (b) turn-off. Denominations: $v_{D S}=$ drain-source voltage, $i_{D}=$ drain current.

temperatures for the Si case have been scaled to correspond to a heat sink with heat pipes to be able to compare the results.

The tests were set up under the following fixed point conditions:

- Carrier based pulse width modulation (PWM)

- Train speed $45 \mathrm{~km} / \mathrm{h}$

- DC-link voltage $640 \mathrm{~V}$

- Phase current 210 Arms

- Varying switching frequency in steps of $1000 \mathrm{~Hz}$

Cooling air flow corresponding to the specified train speed was used to simulate car motion cooling in the test room. The ambient temperature was $20-25^{\circ} \mathrm{C}$ during testing.

Calculations of inverter losses for the tested cases have been performed based on conduction losses as stated in the semiconductor modules datasheets and switching losses as
TABLE I

CALCULATED CONDUCTION AND SWITCHING LOSSES FOR SiC MOSFET IN THE LABORATORY TEST

\begin{tabular}{cccc}
$\begin{array}{c}\text { Switching } \\
\text { frequency }[\mathrm{Hz}]\end{array}$ & $\begin{array}{c}\text { Conduction } \\
\text { losses }[\mathrm{W}]\end{array}$ & $\begin{array}{c}\text { Switching } \\
\text { losses [W] }\end{array}$ & $\begin{array}{c}\text { Total } \\
\text { losses [W] }\end{array}$ \\
\hline 1000 & 39 & 31 & 70 \\
2000 & 39 & 63 & 102 \\
3000 & 39 & 94 & 133 \\
4000 & 39 & 126 & 165 \\
5000 & 39 & 157 & 196 \\
6000 & 39 & 189 & 228 \\
\hline
\end{tabular}

TABLE II

CALCULATED CONDUCTION AND SWITCHING LOSSES FOR Si IGBT IN THE LABORATORY TEST

\begin{tabular}{cccc}
$\begin{array}{c}\text { Switching } \\
\text { frequency [Hz] }\end{array}$ & $\begin{array}{c}\text { Conduction } \\
\text { losses [W] }\end{array}$ & $\begin{array}{c}\text { Switching } \\
\text { losses [W] }\end{array}$ & $\begin{array}{c}\text { Total } \\
\text { losses [W] }\end{array}$ \\
\hline 1000 & 111 & 88 & 199 \\
2000 & 111 & 176 & 287 \\
\hline
\end{tabular}

measured in double pulse tests using the method described in [19]. Conduction losses are assumed to be independent of switching frequency and switching losses are assumed to depend proportionally on switching frequency. Therefore, the detailed loss calculation has been performed solely for the $6000 \mathrm{~Hz}$ case for SiC MOSFET and the $2000 \mathrm{~Hz}$ case for $\mathrm{Si}$ IGBT with the losses for the other cases deduced from those results. The results of the calculations are shown in Table I and Table II.

\section{RESULTS FROM THE LABORATORY TEST}

Measured temperatures for the tests described above are shown in Fig. 5 for $\mathrm{Si}$ and $\mathrm{SiC}$ power devices with varying switching frequencies. The reported values are for fixed point operation taken when thermal equilibrium has been reached for each switching frequency. Heat sink and case temperatures measured under the dies of the power devices are reported both for the transistor and the diode.

The large reduction of power losses when using $\mathrm{SiC}$ instead of $\mathrm{Si}$ can be seen in the test results in Fig. 5. As an example, the transistor case temperature increase over ambient is reduced with $63 \%$ for the case with $2000 \mathrm{~Hz}$ carrier based PWM. It can also be noted the relatively larger benefit of using $\mathrm{SiC}$ at higher switching frequencies when comparing the $1000 \mathrm{~Hz}$ and $2000 \mathrm{~Hz}$ cases.

\section{RESULTS FROM THE FIELD TEST}

The 3-month field test was performed from December 4, 2017 until March 9, 2018. The duration of the test had been decided before the test started. One original Si IGBT inverter on the train was replaced with the $\mathrm{SiC}$ inverter. The train was then used in normal passenger service on the Green Line in Stockholm Metro. Drivers of the train were not informed that it was part of a test, so it can be assumed that they were driving the train as normal. The original switching frequency 


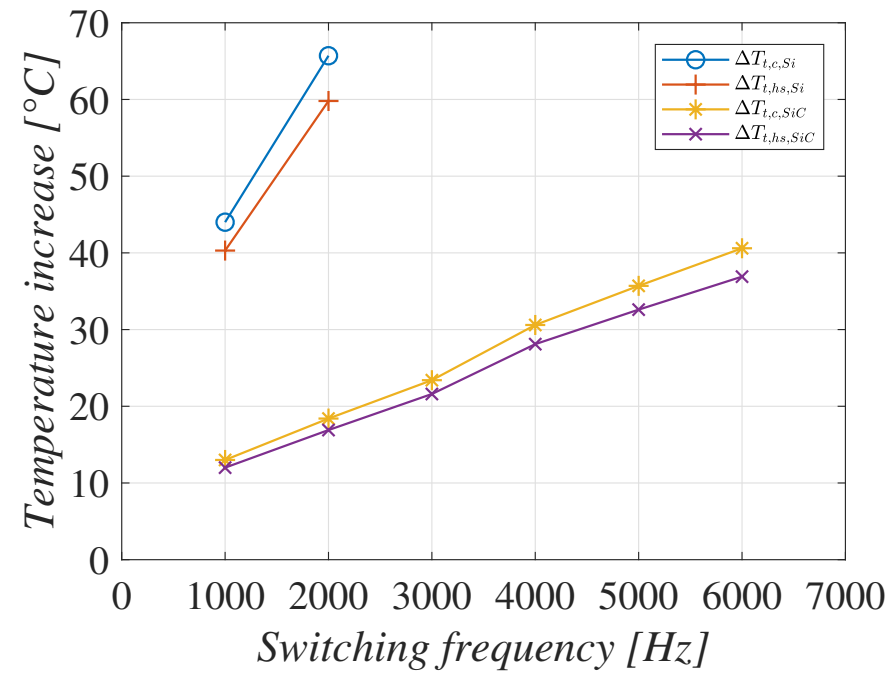

(a) Transistor

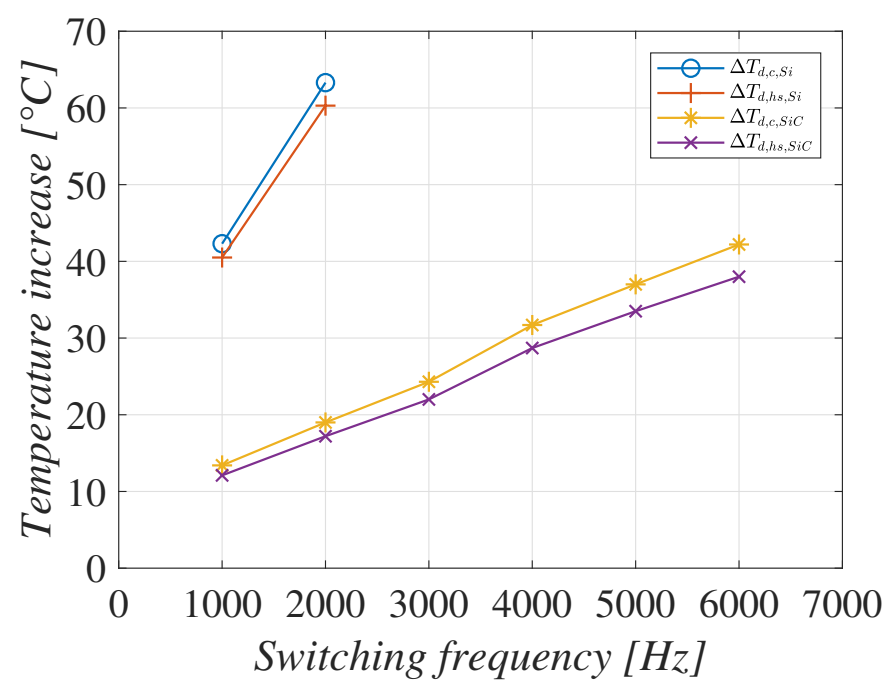

(b) Diode

Fig. 5. Measured heat sink and case temperatures for (a) the transistor and (b) the diode in thermal equilibrium with fixed operation points as described in the text. The reported values are the temperature increase over ambient temperature. Denominations: $\mathrm{t}=$ transistor, $\mathrm{d}=$ diode, $\mathrm{hs}=$ heat sink, $\mathrm{c}=$ case. See text for description of scaling of Si temperatures.

for the carrier based PWM of $1000 \mathrm{~Hz}$ was kept in the field test to avoid time consuming homologation of line interference requirements. The field test was led by Bombardier Transportation in Sweden.

Data from a typical day of operation (specifically March 7, 2018) is shown in Fig. 6. The train is operated in speeds between 0 to $70 \mathrm{~km} / \mathrm{h}$, produced by stator currents varying from 0 to 300 Arms with a $10 \mathrm{~min}$ RMS value of around 100 Arms. During the night the train was parked in a depot, so the initial temperature is around $20^{\circ} \mathrm{C}$ in the figure. The highest measured heat sink temperature during this day was $16{ }^{\circ} \mathrm{C}$. The outdoor temperature was approximately $-1{ }^{\circ} \mathrm{C}$. This agrees well with the measured temperature increase above ambient of $13^{\circ} \mathrm{C}$ measured in the laboratory for $1000 \mathrm{~Hz}$ switching frequency as seen in Fig. 5 (but note that the load cases are not identical).

The test was completed successfully with the SiC inverter working flawlessly during the test. The result that the $\mathrm{SiC}$ power modules could successfully be operated under real world environmental conditions in a traction application increases the confidence in the $\mathrm{SiC}$ technology and takes the technology one step closer to widespread use.

\section{CONCLUSIONS AND DISCUSSION}

Measurement results have been reported from a 3-month field test using a $\mathrm{SiC}$ MOSFET traction inverter operated in a field test on the Green Line in the Stockholm metro system with passengers. To the authors' best knowledge, this is the first time successful results with silicon carbide on a real train are reported in literature. Increased power density is reported compared to the replaced original Si IGBT inverter on the train with a volume reduction of $51 \%$ as well as a weight reduction of $22 \%$. The lower power losses allow the use of car motion cooling in contrast to forced air cooling for the original inverter.

The heat sink temperature was measured to maximum $16^{\circ} \mathrm{C}$ when the outdoor temperature was approximately $-1{ }^{\circ} \mathrm{C}$, with a switching frequency of $1000 \mathrm{~Hz}$ used in the field test.

This field test was performed in a geographic area and season of the year with low ambient temperature. For environments with higher ambient temperatures care must be taken to design the inverter with the temperature dependance of the power losses in mind which is stronger compared to Si IGBTs. Future work will need to address the long-term reliability questions.

Complementing the field test, thermal measurements have been performed in the laboratory comparing the $\mathrm{Si}$ and $\mathrm{SiC}$ semiconductors used in the same power module housing. A decrease of $63 \%$ in transistor case temperature increase over ambient was reported for the laboratory test case with $2000 \mathrm{~Hz}$ carrier based PWM.

In conclusion, the successful completion of the 3-month field test increases the confidence in the SiC MOSFET inverter technology, bringing the customer values of high energy efficiency, lower maintenance and lower noise closer to reality.

\section{ACKNOWLEDGMENT}

The authors would like to thank the Swedish Energy Agency (Energimyndigheten) for the financial support of the work. The authors would also like to thank the fleet owner Storstockholms Lokaltrafik (SL), the operator MTR Tech and the research institute RISE for the cooperation in this project. Finally the authors would like to thank Keijo Jacobs for his contribution.

\section{REFERENCES}

[1] T. Negishi, R. Tsuda, K. Ota, S. Iura, and H. Yamaguchi, "3.3 kV allSiC power module for traction system use," in PCIM Europe 2017; International Exhibition and Conference for Power Electronics, Intelligent Motion, Renewable Energy and Energy Management, May 2017, pp. 1-6. 

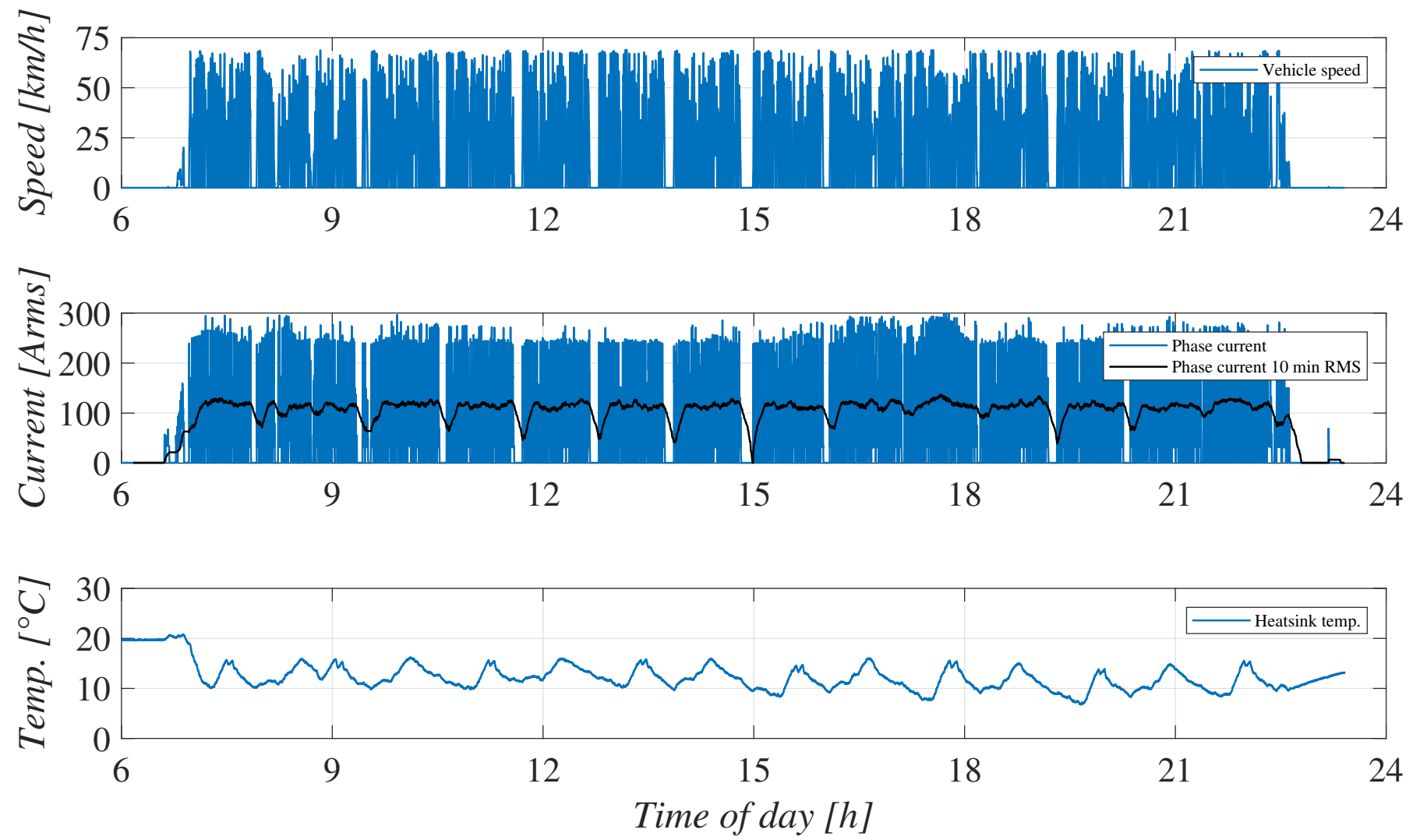

Fig. 6. One typical day of operation of the SiC MOSFET inverter on the Green Line in the Stockholm Metro. Data from March 7, 2018. (a) Train speed in $\mathrm{km} / \mathrm{h}$, (b) inverter phase current with its corresponding 10 min RMS in Arms, (c) inverter heat sink temperature in ${ }^{\circ} \mathrm{C}$.

[2] C. Ionita, M. Nawaz, K. Ilves, and F. Iannuzzo, “Comparative assessment of $3.3 \mathrm{kV} / 400 \mathrm{~A}$ SiC MOSFET and Si IGBT power modules," in 2017 IEEE Energy Conversion Congress and Exposition (ECCE), Oct 2017, pp. 1343-1349.

[3] K. Hamada, S. Hino, N. Miura, H. Watanabe, S. Nakata, E. Suekawa, Y. Ebiike, M. Imaizumi, I. Umezaki, and S. Yamakawa, "3.3 kV/1500 A power modules for the world's first all-SiC traction inverter," Japanese Journal of Applied Physics, vol. 54, no. 4S, p. 04DP07, Feb 2015.

[4] A. Merkert, T. Krone, and A. Mertens, "Characterization and scalable modeling of power semiconductors for optimzied design of traction inverters with Si- and SiC-devices," in 2012 IEEE Vehicle Power and Propulsion Conference, Oct 2012, pp. 647-652.

[5] J. Colmenares, D. Peftitsis, G. Tolstoy, D.-P. Sadik, H.-P. Nee, and J. Rabkowski, "High-efficiency three-phase inverter with SiC MOSFET power modules for motor-drive applications," in 2014 IEEE Energy Conversion Congress and Exposition (ECCE), Sep 2014, pp. 468-474.

[6] J. K. Reed, J. McFarland, J. Tangudu, E. Vinot, R. Trigui, G. Venkataramanan, S. Gupta, and T. Jahns, "Modeling power semiconductor losses in HEV powertrains using $\mathrm{Si}$ and SiC devices," in 2010 IEEE Vehicle Power and Propulsion Conference, Sep 2010, pp. 1-6.

[7] J. Rabkowski, D. Peftitsis, and H.-P. Nee, "Design steps toward a $40-$ kVA SiC JFET inverter with natural-convection cooling and an efficiency exceeding 99.5\%," IEEE Transactions on Industry Applications, vol. 49, no. 4, pp. 1589-1598, Jul 2013.

[8] J. Fabre, P. Ladoux, and M. Piton, "Characterization and implementation of dual-SiC MOSFET modules for future use in traction converters," IEEE Transactions on Power Electronics, vol. 30, no. 8, pp. 4079-4090, Aug 2015.

[9] B. Hull, S. Allen, Q. Zhang, D. Gajewski, V. Pala, J. Richmond, S. Ryu, M. O'Loughlin, E. V. Brunt, L. Cheng, A. Burk, J. Casady, D. Grider, and J. Palmour, "Reliability and stability of $\mathrm{SiC}$ power MOSFETs and next-generation SiC MOSFET," in 2014 IEEE Workshop on Wide Bandgap Power Devices and Applications, Oct 2014, pp. 139-142.
[10] D.-P. Sadik, H.-P. Nee, F. Giezendanner, and P. Ranstad, "Humidity testing of SiC power MOSFETs," in 2016 IEEE 8th International Power Electronics and Motion Control Conference (IPEMC-ECCE Asia), May 2016, pp. 3131-3136.

[11] S. Mbarek, P. Dherbécourt, O. Latry, F. Fouquet, D. Othman, M. Berkani, and $\mathrm{S}$. Lefebvre, "Robustness study of SiC MOSFET under harsh electrical and thermal constraints," in Proc. CENICS: The Seventh Int. Conf. Adv. Circuits, Electron. Micro-electron., Nov 2014, pp. 11-15.

[12] M. Kitabatake, H. Sako, M. Sasaki, T. Yamashita, K. Tamura, K. Yamada, O. Ishiyama, J. Senzaki, and H. Matsuhata, "Electrical characteristics/reliability affected by defects analyzed by the integrated evaluation platform for SiC epitaxial films," in Materials Science Forum, vol. 778, May 2014, pp. 979-984.

[13] L. Fursin, X. Li, Z. Li, M. O'Grady, W. Simon, and A. Bhalla, "Reliability aspects of $1200 \mathrm{~V}$ and $3300 \mathrm{~V}$ silicon carbide MOSFETs," in 2017 IEEE 5th Workshop on Wide Bandgap Power Devices and Applications (WiPDA), Oct 2017, pp. 373-377.

[14] M. Furuhashi, S. Tomohisa, T. Kuroiwa, and S. Yamakawa, "Practical applications of SiC-MOSFETs and further developments," Semiconductor Science and Technology, vol. 31, no. 3, p. 034003, Jan 2016.

[15] E. Velander, G. Bohlin, Å. Sandberg, T. Wiik, F. Botling, M. Lindahl, G. Zanuso, and H.-P. Nee, "An ultralow loss inductorless $d v / d t$ filter concept for medium-power voltage source motor drive converters with SiC devices," IEEE Transactions on Power Electronics, vol. 33, no. 7, pp. 6072-6081, Jul 2018.

[16] E. V. Brunt, D. J. Lichtenwalner, R. Leonard, A. Burk, S. Sabri, B. Hull, S. Allen, and J. W. Palmour, "Reliability assessment of a large population of $3.3 \mathrm{kV}, 45$ A 4H-SiC MOSFETs," in 2017 29th International Symposium on Power Semiconductor Devices and IC's (ISPSD), May 2017, pp. 251-254.

[17] D. Kawase, M. Inaba, K. Horiuchi, and K. Saito, "High voltage module with low internal inductance for next chip generation - next high power density dual (nHPD2)," in Proceedings of PCIM Europe 
2015; International Exhibition and Conference for Power Electronics, Intelligent Motion, Renewable Energy and Energy Management, May 2015, pp. 1-7.

[18] T. Ishigaki, S. Hayakawa, T. Murata, T. Nozoe, H. Onose, H. Miki, M. Sagawa, T. Oda, K. Yasui, D. Kawase, Y. Takayanagi, R. Yamada, T. Masuda, and N. Tega, "3.3 kV/450 A full-SiC nHPD2 (next high power density dual) with smooth switching," in PCIM Europe 2017; International Exhibition and Conference for Power Electronics, Intelligent Motion, Renewable Energy and Energy Management, May 2017, pp. 1-6.

[19] E. Velander, L. Kruse, T. Wiik, A. Wiberg, J. Colmenares, and H.-P. Nee, "An IGBT turn-on concept offering low losses under motor drive $\mathrm{dv} / \mathrm{dt}$ constraints based on diode current adaption," IEEE Transactions on Power Electronics, vol. 33, no. 2, pp. 1143-1153, Feb 2018. 